9 Albarbarawi O, Barton A, Miller D, et al. Characterization and validation of an isotope-dilution LC-MS/MS method for quantification of total desmosine and isodesmosine in plasma and serum. Bioanalysis 2013; 5: 1991-2001.

10 Rabinovich RA, Miller BE, Wrobel K, et al. Circulating desmosine levels do not predict emphysema progression but are associated with cardiovascular risk and mortality in COPD. Eur Respir J 2016; 47: 1365-1373.

11 Huang JT, Chaudhuri R, Albarbarawi O, et al. Clinical validity of plasma and urinary desmosine as biomarkers for chronic obstructive pulmonary disease. Thorax 2012; 67: 502-508.

12 Lindberg CA, Engström G, de Verdier MG, et al. Total desmosines in plasma and urine correlate with lung function. Eur Respir J 2012; 39: 839-845.

13 Ma S, Lin YY, Tartell L, et al. The effect of tiotropium therapy on markers of elastin degradation in COPD. Respir Res 2009; 10: 12 .

14 Celli B, Decramer M, Leimer I, et al. Cardiovascular safety of tiotropium in patients with COPD. Chest 2010; 137: $20-30$.

\title{
The effect of hypoxia and re-oxygenation on adipose tissue lipolysis in COPD patients
}

To the Editor:

Severe chronic obstructive pulmonary disease (COPD) is a progressive disease associated with excessive mortality; however, mechanisms driving disease progression remain unclear [1]. A pro-inflammatory state, metabolic impairments and respiratory muscle weakness contribute to deterioration of lung function $[1,2]$. Furthermore, a poor COPD prognosis appears to be associated with unintentional weight loss [3, 4], which has been observed in $\sim 50 \%$ of severe COPD patients [5].

Adipose tissue secretion of pro-inflammatory substances is modified by tissue $\mathrm{O}_{2}$ levels [6]. Transient drops in blood oxygenation dropping to arterial oxygen saturation measured by pulse oximetry $\left(\mathrm{SpO}_{2}\right)$ levels of $60-70 \%$ have been shown to induce profound adipose tissue hypoxia with oxygen tension $\left(\mathrm{PO}_{2}\right)$ levels as low as $30-40 \mathrm{mmHg}$ [7], which resemble levels typically observed in obesity and which are associated with augmented lipolysis and elevated levels of circulating free fatty acids (FFA) [8, 9]. In fact, elevated plasma FFA levels in COPD patients [10] could be due to increased adipose tissue lipolysis. Considering that chronic exposure to higher plasma FFA concentrations can lead to lipotoxicity in cardiac muscle and impaired energy metabolism in skeletal (respiratory) muscle, it can be hypothesised that enhanced lipolysis worsens the COPD prognosis through its negative impact on respiratory muscle function, progression of right heart failure, and development of cachexia.

Regulation of adipose tissue lipolysis in COPD patients is potentially associated with adipose tissue hypoxia, activation of the sympathetic autonomic nervous system and/or elevation of pro-inflammatory cytokines [11, 12]. Additionally, elevated plasma levels of lipolysis-stimulating natriuretic peptides (atrial natriuretic peptide (ANP) and brain natriuretic peptide (BNP)) have been found in COPD patients, which provides an additional mechanism for enhanced lipolysis [13].

The aim of this study was to investigate the lipolytic response, of adipose tissue, to acute changes in arterial oxygen levels and to assess the role of acute ANP and catecholamine administration in a group of severe COPD patients.

Eight subjects (four men, aged 61.4 \pm 2.8 years, body mass index (BMI) $24.4 \pm 0.8 \mathrm{~kg} \cdot \mathrm{m}^{-2}$ ) with severe COPD (GOLD IV category diagnostic criteria) who had been prescribed long term oxygen therapy (LTOT) $>1$ year were recruited. Exclusion criteria included acute exacerbation of COPD, other acute or decompensated illnesses (inflammatory, endocrine), unstable body weight over the 3 months prior to entering the study, age $>75$ years and cancer. All subjects gave written informed consent and the study was approved by the Ethics Committee of the Third Faculty of Medicine, Charles University in Prague.

Two microdialysis probes (20.000 Da cut-off, CMA Microdialysis, Kista, Sweden) were inserted into the subcutaneous abdominal adipose tissue. The probes were perfused with Ringer's solution (Baxter, Prague, Czech Republic) supplemented with $1.7 \mathrm{~g} \cdot \mathrm{L}^{-1}$ ethanol with or without $10^{-6} \mathrm{~mol} \cdot \mathrm{L}^{-1}$ ANP or $10^{-6} \mathrm{~mol} \cdot \mathrm{L}^{-1}$ adrenaline. The outflowing dialysate was collected for glycerol (Randox Laboratories, Crumlin, UK), ethanol (BioVision, Milpitas, CA, USA) and urea (Abcam, Cambridge, UK) quantification. The dialysate glycerol concentration served as a marker of lipolysis, while the ethanol inflow/outflow ratio and urea 
concentrations were used to assess changes in tissue blood flow. After introduction of intravenous cannulas and microdialysis probes, supplemental oxygen delivery was interrupted for $3 \mathrm{~h}$ to induce hypoxaemia. The dialysate was collected at $20 \mathrm{~min}$ intervals. Baseline sampling for $60 \mathrm{~min}$ was followed by a $60 \mathrm{~min}$ perfusion with $10^{-6} \mathrm{~mol} \cdot \mathrm{L}^{-1}$ human recombinant ANP (Neosystem, Strasbourg, France) or $10^{-6} \mathrm{~mol} \cdot \mathrm{L}^{-1}$ adrenaline (Zentiva, Prague, Czech Republic). Subsequently, subjects were administered 100\% oxygen for $240 \mathrm{~min}$ through a nasal cannula $\left(1-2 \mathrm{~L} \cdot \mathrm{min}^{-1}\right)$ according to their individual recommendations for LTOT. After $180 \mathrm{~min}$, three baseline dialysate samples were collected and probes were again perfused with freshly prepared $10^{-6} \mathrm{~mol} \cdot \mathrm{L}^{-1} \mathrm{ANP}$ or $10^{-6}$ adrenaline for $60 \mathrm{~min}$.

Fasting plasma samples were stored at $-80^{\circ} \mathrm{C}$. Plasma FFA (Wako Chemicals Inc., Richmond, VA, USA), insulin (EIA insulin kit; Mercodia, Uppsala, Sweden), glucose (Biotrol kit; Merck-Clevenot, Paris, France), and ANP (RIA kit; Peninsula Laboratories, San Carlos, CA, USA) were measured. Dialysate glycerol and urea were measured using colorimetric assays (Sigma-Aldrich, St. Louis, MI, USA), and the ethanol was determined using a colorimetric/fluorometric assay (Abcam).

Differences in spontaneous lipolysis between hypoxic and normoxic states were analysed using the paired T-test. The effect of in situ ANP and adrenaline administration was assessed by calculation of drug-induced fold-changes in lipolysis and analysed using a paired t-test. Data are presented as mean \pm SEM, and $\mathrm{p}<0.05$ was considered statistically significant.

Interruption of supplemental oxygen resulted in blood hypoxaemia with an average haemoglobin saturation of $88.5 \pm 1.8 \%$. After supplemental oxygen was resumed at flow rates identical to recommended $\mathrm{O}_{2}$ flow rates for LTOT, haemoglobin saturation normalised to $97.7 \pm 0.6 \%(\mathrm{p}<0.05)$. Plasma ANP $(0.5 \pm 0.1$ versus $\left.0.5 \pm 0.1 \mathrm{ng} \cdot \mathrm{mL}^{-1}\right)$ and FFA levels $\left(429.9 \pm 52.5\right.$ versus $\left.452.4 \pm 36.8 \mu \mathrm{mol} \cdot \mathrm{L}^{-1}\right)$ remained unchanged after resumption of supplemental $\mathrm{O}_{2}$.

Spontaneous lipolysis, decreased by $24 \%$ after reoxygenation (dialysate glycerol: $170.4 \pm 70.1$ versus $\left.129.9 \pm 79.2 \mu \mathrm{mol} \cdot \mathrm{L}^{-1} ; \mathrm{p}<0.05\right)$ while adipose tissue blood flow remained unchanged as demonstrated by the stable ethanol in-flow/out-flow ratio $(34.9 \pm 5.6$ versus $36.5 \pm 5.1 \%, \mathrm{p}>0.95)$ and dialysate urea concentration $\left(0.9 \pm 0.1\right.$ versus $\left.0.9 \pm 0.1 \mathrm{mmol} \cdot \mathrm{L}^{-1}\right)$. Furthermore, adipose tissue lipolysis, stimulated by local ANP administration, was lower in normoxia compared to hypoxia (fold change: $4.41 \pm 0.26$ versus $3.75 \pm 0.23 ; \mathrm{p}<0.05$ ) while adrenaline-induced lipolysis was not affected by reoxygenation (fold change: $4.27 \pm 0.28$ versus $4.04 \pm 0.39$; $\mathrm{p}=0.51$ ) (figure 1).

The present study provides direct evidence that basal and stimulated lipolysis is enhanced in subcutaneous adipose tissue in hypoxic COPD patients and that administration of exogenous oxygen can inhibit lipolysis. Although enhanced lipolysis was observed in hypoxic adipose tissue in obesity and obstructive sleep apnoea syndrome $[8,9]$, we have extended these observations to chronically hypoxic COPD patients. In fact, augmented lipolysis and associated weight loss represent an important factor inducing metabolic impairments in heart [14] and skeletal muscle and might also contribute to progression of COPD by inducing cachexia and muscle weakness.

Plasma ANP levels are increased in COPD patients, particularly in those with right heart failure and pulmonary hypertension [13]. In-situ ANP administration not only increased lipolysis, confirming the potent lipolysis-stimulating effects of ANP [15], but this effect was augmented in hypoxic conditions, probably via receptor and/or post-receptor mechanisms, since plasma ANP levels remained unchanged. In contrast, the lipolytic response to adrenaline was not affected by hypoxia, probably due to adrenergic receptor desensitisation.

a)

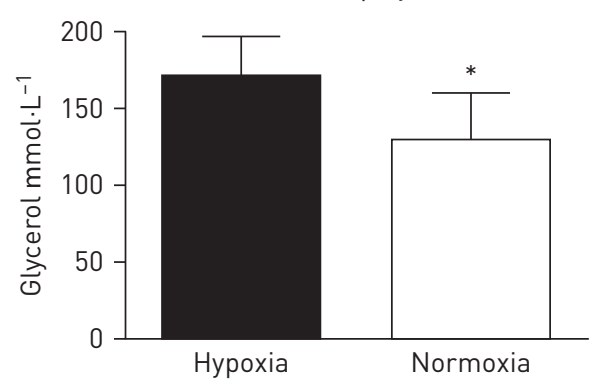

b) ANP-induced lipolysis

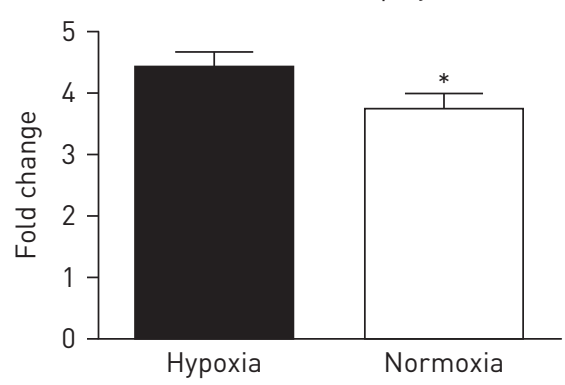

c) Adrenaline-induced lipolysis

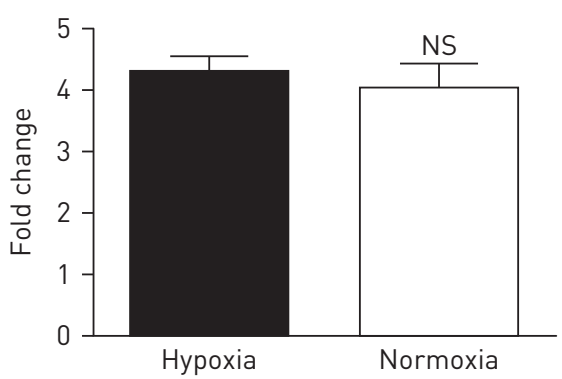

FIGURE 1 Adipose tissue spontaneous lipolysis and blood flow. a) Basal adipose tissue lipolysis assessed by extracellular glycerol adipose tissue concentration; b) cumulative adipose tissue lipolytic response after in situ administration of $10^{-6}$ mol. $\mathrm{L}^{-1}$ atrial natriuretic peptide for $1 \mathrm{~h}$; c) cumulative adipose tissue lipolytic response after in situ administration of $10^{-6} \mathrm{~mol} \cdot \mathrm{L}^{-1}$ adrenaline for $1 \mathrm{~h}$. Data are presented as mean $\pm \mathrm{SEM}$, $\mathrm{n}=8$ for adrenaline and $\mathrm{n}=7$ for ANP group. *: $\mathrm{p}<0.05$ for comparison between hypoxic and normoxic conditions; NS: not significant. 
The study was limited by its focus on severe COPD patients, the use of pharmacological concentrations of ANP and adrenaline in microdialysis perfusions, and by the use of semi-quantitative methods for assessing adipose tissue blood flow. It should be noted that plasma FFA levels remained unchanged during the study, suggesting that FFA re-esterification is decreased in adipose tissue after reoxygenation. Establishing a causal role of ANP in COPD-associated lipolysis requires specific ANP receptor antagonists, which are currently not available for human use.

In conclusion, this study showed that spontaneous and ANP-stimulated subcutaneous adipose tissue lipolysis is enhanced during acute withdrawal of supplemental oxygen in COPD patients and appears to exert lipotoxic effects. By demonstrating that reoxygenation decreased adipose tissue lipolysis, the study underscores the need for long term oxygen therapy in patients with hypoxaemia.

$\circ$ @ERSpublications

Oxygen administration inhibits spontaneous and ANP-stimulated lipolysis in adipose tissue in severe COPD http://ow.ly/ZVg53022Yah

\begin{abstract}
Andrea Plihalova ${ }^{1,2}$, Hana Bartakova ${ }^{3}$, Martina Vasakova ${ }^{4}$, Sumeet Gulati ${ }^{2}$, Isabelle deGlisezinski ${ }^{5,6}$, Vladimir Stich ${ }^{2,7}$ and Jan Polak ${ }^{1,2,7}$

${ }^{1}$ 2nd Internal Medicine Department, Vinohrady Teaching Hospital, Prague, Czech Republic. ${ }^{2}$ Center for Research on Diabetes, Metabolism and Nutrition, Third Faculty of Medicine, Charles University in Prague, Prague, Czech Republic.

${ }^{3} 1$ st Dept of Tuberculosis and Respiratory Diseases, First Faculty of Medicine, Charles University in Prague and General University Hospital in Prague, Prague, Czech Republic. ${ }^{4}$ Dept of Respiratory Medicine, First Faculty of Medicine, Charles University in Prague and Thomayer Hospital, Prague, Czech Republic. ${ }^{5}$ INSERM, UMR1048, Obesity Research Laboratory, Institute of Metabolic and Cardiovascular Diseases, Toulouse, France. ${ }^{6}$ University of Toulouse, UMR1048, Paul Sabatier University and Depts of Sports Medicine, Toulouse University Hospitals, Toulouse, France. ${ }^{7}$ Dept of Sports Medicine, Third Faculty of Medicine, Charles University in Prague, Prague, Czech Republic.
\end{abstract}

Correspondence: Jan Polak, Center for Research on Diabetes, Metabolism and Nutrition, Third Faculty of Medicine, Charles University in Prague, Ruska 87, Prague 10, 100 00, Czech Republic. E-mail: jan.polak@lf3.cuni.cz

Received: Dec 302015 | Accepted after revision: June 212016 | First published online: Sept 012016

Support statement: The study was supported by grants from the Czech Science Foundation (GACR P304/13-27735S), the Ministry of Health of the Czech Republic (grant number 15-30155A) and Charles University in Prague (SVV 2016/ 260276 and PRVOUK P31). Funding information for this article has been deposited with the Open Funder Registry.

Conflict of interest: Disclosures can be found alongside this article at erj.ersjournals.com

\title{
References
}

1 Stockley RA. Progression of chronic obstructive pulmonary disease: impact of inflammation, comorbidities and therapeutic intervention. Curr Med Res Opin 2009; 25: 1235-1245.

2 Larsson K. Inflammatory markers in COPD. Clin Respir J 2008; 2: Suppl 1, 84-87.

3 Landbo C, Prescott E, Lange P, et al. Prognostic value of nutritional status in chronic obstructive pulmonary disease. Am J Respir Crit Care Med 1999; 160: 1856-1861.

4 Prescott E, Almdal T, Mikkelsen KL, et al. Prognostic value of weight change in chronic obstructive pulmonary disease: results from the Copenhagen City Heart Study. Eur Respir J 2002; 20: 539-544.

5 Schols AM, Soeters PB, Dingemans AM, et al. Prevalence and characteristics of nutritional depletion in patients with stable COPD eligible for pulmonary rehabilitation. Am Rev Respir Dis 1993; 147: 1151-1156.

Trayhurn P. Hypoxia and adipose tissue function and dysfunction in obesity. Physiol Rev 2013; 93: 1-21.

7 Reinke C, Bevans-Fonti S, Drager LF, et al. Effects of different acute hypoxic regimens on tissue oxygen profiles and metabolic outcomes. J Appl Physiol 2011; 111: 881-890.

8 Ye J. Emerging role of adipose tissue hypoxia in obesity and insulin resistance. Int J Obes (Lond) 2009; 33: 54-66.

9 Weiszenstein M, Shimoda LA, Koc M, et al. Inhibition of lipolysis ameliorates diabetic phenotype in a mouse model of obstructive sleep apnea. Am J Respir Cell Mol Biol 2016; 55: 299-307.

10 Jakobsson EJ, Jorfeldt L. Blood fuel metabolites at rest and during exercise in patients with advanced chronic obstructive pulmonary disease with and without chronic respiratory failure. Respiration 1990; 57: 304-309.

11 Andreas S, Haarmann H, Klarner S, et al. Increased sympathetic nerve activity in COPD is associated with morbidity and mortality. Lung 2014; 192: 235-241.

12 Gan WQ, Man SFP, Senthilselvan A, et al. Association between chronic obstructive pulmonary disease and systemic inflammation: a systematic review and a meta-analysis. Thorax 2004; 59: 574-580.

13 Vonk-Noordegraaf A, Haddad F, Chin KM, et al. Right heart adaptation to pulmonary arterial hypertension: physiology and pathobiology. J Am Coll Cardiol 2013; 62: D22-D33.

14 Polak J, Kotrc M, Wedellova Z, et al. Lipolytic effects of B-type natriuretic peptide 1-32 in adipose tissue of heart failure patients compared with healthy controls. J Am Coll Cardiol 2011; 58: 1119-1125.

15 Lafontan M, Moro C, Berlan M, et al. Control of lipolysis by natriuretic peptides and cyclic GMP 1. Trends Endocrinol Metab 2008; 19: 130-137. 